\title{
Adolescent Science Students' Perception of Acquisition of Environmental Health Skills through School Health Programme in Nigeria
}

\author{
Anthonia U. Ejifugha, PhD \\ Department of Physical and Health Education, Alvan Ikoku Federal College of Education, Owerri-Nigeria
}

Jacinta A. Opara, PhD

Center for Environmental Education Universidad Azteca Chalco-Mexico

\section{Doi:10.5901/jesr.2015.v5n1p193}

\begin{abstract}
The study was on science students' perception of acquisition of environmental health (sanitation) skills among adolescents in Imo State through the school health programme. Six research questions and five hypotheses guided the study. The descriptive research design was used for the study. Using the multi- stage sampling technique, 565 science students were sampled for the study. The study revealed that all the items presented in the study were perceived to be very important environmental sanitation skills by students. These covered water pollution, disposal of human waste, food handing, and environmental cleanliness. Gender, educational qualification of parents, and person responsible for family health were significant on the acquisition of environmental sanitation skills while family typology and status of single parenthood had no influence on acquisition of health skills. The perception of students whose parents hold PhD was significantly higher than those with ordinary National Diploma (OND), Nigeria Certificate in Education (NCE) and First School Leaving Certificate (FSLC). The perception of those whose father cares most was significantly higher than those whose mother does not care or cares a little. In view of the results of the study, it was recommended that the Ministry of Education should develop procedures for inculcating these skills in adolescents as a way of life and as a school requirement for graduation. Parental responsibility in health care is fundamental in acquisition of health skills.
\end{abstract}

Keywords: Science, Adolescents, Health, School, Teaching, Environmental Sanitation, Skills, Students

\section{Introduction}

Environmental education is a core aspect of Science teaching and learning. Sanitation is an integral part of community and environmental health. Teaching for health is one viable function of the health teacher in school. Health is considered as one of the fundamental human values. (Zigler,1975).Historically personal health runs concurrently with environmental health. Acquisition of environmental health skills among adolescents is the main thrust of this paper. Just as life skills is a recent development in education literatures so also skill based health education is a recent development in World Health Organization's literature (Federal Ministry of Education, 2006). Acquisition of health skills is focused on the content areas of health education one of which is environmental sanitation.

Environment has been described as comprising of physical and social conditions where people live which usually refers to conditions such as air, water, land in which people, annual of various types and plants exist (Offing, 2011). It is further described as all that which is external to the individual human host. It is usually streamlined into physical, biological, social, and cultural all of which can influence health status of the citizenry (Last, 1998). Environmental sanitation could be described as all the factors in man's physical environment which exercise or may exercise deleterious effect on his survival. In the past sanitation concentrated on disposal of human waste only but currently it encompasses the whole field of controlling the environment with the view of preventing diseases and promoting health (WHO 1995 in Kwasan 2012).

Environment is described by World Bank Group (2012) as a complex set of physical geographical, biological, social, cultural and political conditions that surround an individual or organism and which ultimately determine the form and nature of its survival. In addition to that environmental sanitation is the principle of hygienic conditions in the environment to promote public health and ensure sustainable development (UNICEF, 1999).

Furthermore according to WHO (2012), environmental sanitation refers to the control of all those factors in the human environment which directly or indirectly exercise some influence on health and survival of man. The control is 
achieved through conscious prevention of infectious diseases seeing to the proper efficient and sanitary disposal of waste, (both dry and wet) water pollution control, food hygiene and food quality control. In addition to that environmental sanitation policy (2010) stated the components of environmental sanitation as embracing solid waste disposal, adequate potable water supply, school sanitation, personal hygiene and pest and vector control.

In collaboration with the above, Conjecture Corporation (2003) defined environment sanitation skills as the strategies that equip an individual with adequate information on how to keep his surroundings free from harmful substances thereby improving the quality of the environment, and reducing the amount of diseases. Skill is often a word interchanged used with concept such as competence, intervention and techniques (O'Hagen, 1996). corroborating with Nkwocha \& Olusolu (1994) maintained that sanitation includes maintenance of clean environment, adopting good food and milk hygiene, collection and disposal of refuse and waste supply of safe water, provision of decent housing and convenient sanitation, prevention of pollution of all kinds, and maintenance of proper personal hygiene.

Olusolu (1994) maintained that sanitation includes: maintenance of clean environment adopting good food and milk hygiene; collection and disposal of refuse and waste. supply of hygienic safe water; provision of decent housing and convenient sanitation; prevention of pollution of all kinds; and maintenance of proper personal hygiene..

Wellford (1958) in Trevithick (2011) conceptualized skills as having three main characterizes: Skills involve an organized and coordinated activity in relation to an object or situation in ways of performance 'Skills are gradually learnt through repeated experiences;

Skills involve actions that are ordered and coordinated in a temporal sequence or in a chronological order.Trevithick (2011) further outlined three levels of skills: Basic skills - foundational skills; Intermediate skills - skills for dealing with difficult situations,

Advanced skill - superior skills for working with problems that are multifaceted and intractable. ;Additionally, Trevithick further classified skills as generalist skills and specialist skills This work on environmental health skills concentrates on basic environmental sanitation skills which automatically fall into generalist skills.

School Health programme is a service of harmonized projects or organized activities in the school environment for the promotion of the health and development of the school community. The school health programme is one of the strategies for the achievement of health for all (HFA) declaration, education and health related Millennium Development Grabs (MDG) and the National Economic Empowerment and Development Strategy (NEED) Federal Ministry of Education (2006). The above literature introduced the concept of skill based health education which has motivated the researcher to survey the health skills in the content area of environmental sanitation.

Contemporary school health programme should focus on unifying the compartmentalized components of the school health programme viz: skill based health education, school health services, school feeding services, and healthful school living and school and community relations. This study surveys the acquisition of health skill through the school health programme with emphasis on the skills to be acquired by the students and possible factors that may influence the acquisition of those environmental health skills.

\section{Statement of the Problem}

The presence of environmental nuisance in the form of indiscriminate dropping of refuse all over the country is a source of concern. This unbecoming behavior fills the drainage system with refuse which facilitates the breeding of mosquitoes and the associated disease. To address this problem, the Nigerian government lunched monthly clean-up campaign which has not actually ameliorated the problem but creates huge financial waste for the government, through diseases and unsightly environment. Yassi Kjellstron, De Kok and Guidotle (2001) in lloh and Mbama (2012) reported that the impact of environmental degradation stirs up a wide range of health problems. They buttressed that millions of people are exposed to unnecessary biological and chemical hazards in their living and working environment due to poor attitude towards environmental sanitation.

UNICEF (1999) declared that sanitation and spread of communicable diseases are synonymous. A number of gastro intestinal health problem results from unsatisfactory conditions of the environment. According to UNICEF, one gram of human feaces habours about 10,000,000 virus; 1,000,000 bacteria; 1,000 parasite cyst; and 1,000 parasite eggs. Since environmental sanitation skills are health skills their acquisition will ameliorate any health problem that could be generated through poor sanitation.

Consequently the curiosity of this study is to identify the environmental sanitation skills that would be acquired by secondary school students in Imo State. The study will further identify the environmental sanitation skills and will further determine whether gender, family typology, status of single parenthood, educational qualification of parents and family 
health care provider have influence on acquisition of environmental sanitation skills.

\section{Method}

The descriptive research design was used for the study both descriptive and analytical survey. Gray (1976) maintained that survey describes phenomena as they exist in their natural setting. Ogueri and Oparah (2007) used survey for their work on solid waste generation and management practices as correlates of health status of people in Imo State. The population of the study consisted of all secondary school students in Imo State. Using the multi stage sampling technique, 565 science students (ie those offering science stream) constituted the sample size for the study. A structured questionnaire consisting of 12 items was the instrument for data collection. Face validity using three jurors from health education, was used in validating the instrument. The reliability coefficient was 0.76 . The data was analyzed using descriptive and analytical statistics.

\section{Result of the Study}

Table 1: Health Skills in Environmental Sanitation

\begin{tabular}{llcc}
\hline Environmental Sanitation Skills & $\bar{x}$ & SD & Decision \\
\hline 1. $\quad$ Sweep our homes and schools regularly & 2.92 & 0.28 & very important \\
2. $\quad \begin{array}{l}\text { Perform simple methods of purification of water } \\
\text { before use/drinking }\end{array}$ & 2.80 & 0.42 & very important \\
3. Safeguard or preserve community water sources & & & \\
$\quad$ from contamination and pollution & 2.67 & 0.56 & very important \\
4. Proper collection, storage and disposal of refuse from & & & \\
$\quad$ homes and schools & 2.78 & 0.48 & very important \\
5. Empty drains (gutter). & 2.70 & 0.54 & very important \\
6. Avoid disposing of refuse in gutters. & 2.74 & 0.52 & very important \\
7. Cutting of grass around our homes, offices, churches or & & & \\
$\quad$ keep bushes low. & 2.79 & 0.47 & very important \\
8. Plant flowers/trees to beautify our surroundings. & 2.51 & 0.58 & very important \\
9. Wash cooking and eating utensils regularly e.g. pots, plates. & 2.84 & 0.40 & very important \\
10. Adequately store and preserve cooked and uncooked foods & 2.55 & 0.64 & very important \\
11. Wash toilets and bathroom regularly & 2.60 & 0.58 & very important \\
12. Use of pesticides and insecticide in our surrounding & 2.60 & 0.58 & very important \\
$\quad \quad$ Grand $\bar{x}$ \& SD & $\mathbf{2 . 7 2}$ & $\mathbf{0 . 2 7}$ & very important \\
\hline
\end{tabular}

Table 1 shows a grand mean score of 2.72 (within SD of 0.27 ) which falls with $2.50-3.00$. This implies that student's perception of the skills for health to be acquired in environmental health is very important. The table further shows that all the 12 skills in environmental sanitation had mean scores ranging from 2.51-2.92 which fall between $2.50-3.00$. This implies that students perceived all the environmental sanitation skills as very important for the acquisition of skills for health. The table also shows that the standard deviation values which range from 0.28 to 0.57 are not close together, implying student's responses were far apart. Table 1 show that skill_1, with a mean score of 2.91, has the highest mean score in terms of students' perception of the health skill to be acquired in Environmental Sanitation. This is followed by skill_9, with a mean score of 2.84, while skill_8, with a mean score of 2.51 has the lowest mean score in terms of students' perception of the health skill to be acquired in Environmental Sanitation. Students' perception of each of the twelve (12) health skills to be acquired in Environmental Sanitation, considered in the study, can be said to be above average, since the associated mean scores are all greater than the expected value of 2.50 .

\subsection{Hypothesis 1}

Gender does not have any significant effect on students' perception of health skills to be acquired in Environmental Sanitation. Data testing this hypothesis are contained in Table 2. 
Table 2: Two Sample t-tests for the Effect of Gender on Students' Perception of Health Skills to be acquired in Environmental Sanitation

Two Sample t-tests for the Means of unit_area_1 within gender
\begin{tabular}{ccccc} 
Sample statistics \\
\multicolumn{6}{l}{ Group } & $\mathrm{N}$ & Mean & Std. Dev. & Std. Error \\
& & & & \\
\hline female & 285 & 2.76 & 0.26 & 0.0155 \\
male & 280 & 2.66 & 0.27 & 0.0163
\end{tabular}

Hypothesis Test

\begin{tabular}{lcrr}
\hline If Variances Are & $t$ statistic & Do & Pr $>t$ \\
\hline Equal & 4.374 & 563 & $<.0001$ \\
Not Equal & 4.372 & 561.07 & $<.0001$ \\
\hline
\end{tabular}

Table 2 gives the mean scores for female, perception $\left(x^{-}=2.77\right)$ which is slightly higher than that of male $\left(x^{-}=2.67\right)$. This implies that female perception of skills for health to be acquired in environmental sanitation falls within 2.50-300. This implies that female and male students perceived the health skills to be acquired in environmental sanitation through the school health programme very important. Furthermore, the table gives the t-calculated value for the mean differences as 4.37 with a significance probability of $<0.0001$, which is less than 0.05 . Thus the test is significant at $5 \%$ level of significance. We therefore conclude that gender has a significant effect on students' perception of health skills to be acquired in Environmental Sanitation The perception of the female students is significantly higher than that of their male counterparts, in terms of health skills to be acquired in Environmental Sanitation.

\subsection{Hypothesis 2}

Students' family typology does not have any significant effect on students' perception of health skills to be acquired in Environmental Sanitation. Data testing this hypothesis are contained in Table 3

Table 3: Two Sample t-tests for the Effect of Family Typology on Students' Perception of Health Skills to be acquired in Environmental Sanitation

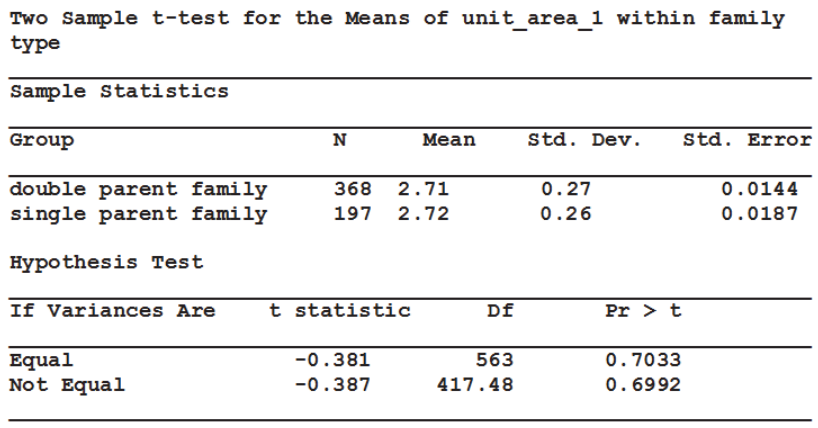

Table 3 gives the mean scores for students with double parents and single parent family typology, on students' perception of health skills to be acquired in Environmental Sanitation, as $\left(x^{-}=2.71\right)$ and $\left(x^{x}=2.72\right)$, respectively This implies that students with single and double parent family typology perceived the health skills to be acquired in environmental sanitation very important..

Furthermore, the table gives the $t$-calculated value for the mean differences as -0.38 with a significance probability of 0.7033 , which is greater than 0.05 . Thus the test is not significant at $5 \%$ level of significance. We, therefore, conclude that students' family typology does not significantly affect students' perception of health skills to be acquired in Environmental Sanitation. The perception of the students with single parent family typology is not the significantly same as those of students with double parent family typology, in terms of health skills to be acquired in Environmental 
Sanitation through school health programme.

\subsection{Hypothesis 3}

Students' perception of health skills to be acquired in Environmental Sanitation is not significantly affected by status of single parenthood. Data testing this hypothesis are contained in Table 4

Table 4:_ANOVA for the Effect of Status of Single Parenthood on Students' Perception of Health Skills to be acquired in Environmental Sanitation

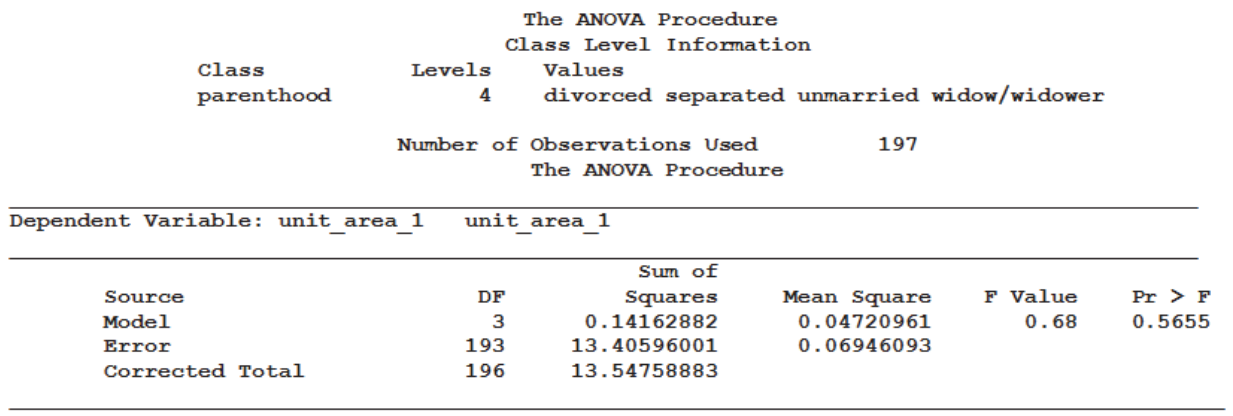

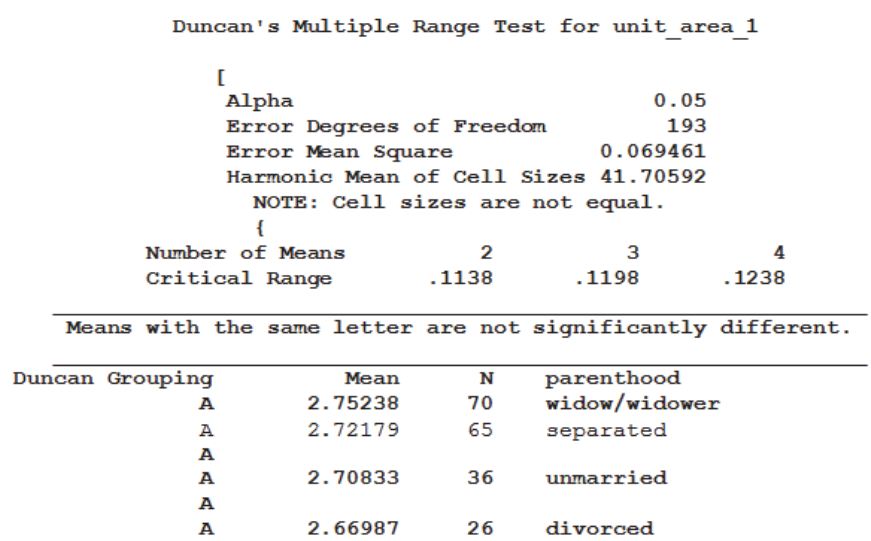

Table 4 shows that students, whose single parents are widows or widowers $(\bar{x}=2.75)$ have the highest perception of health skills to be acquired in Environmental Sanitation. This is followed by students whose single parents are separated $\left(x^{-}=2.72\right)$, and students whose single parents are unmarried $\left(x^{-}=2.71\right)$. Students, whose single parents are divorced have mean score of $(x=2.67)$ implying that these categories of single parenthood perceived health skills to be acquired in environmental sanitation as very important.

Furthermore, the table gives the F-value for the mean differences as 0.68 with a significance probability of 0.57 , which is greater than 0.05 . Thus the test is not significant at $5 \%$ level of significance. We, therefore, conclude that students' perception of health skills to be acquired in Environmental Sanitation is not significantly affected by status of single parenthood. This is confirmed by Duncan's multiple range test, which assigned the same Duncan's grouping letter, $\mathrm{A}$, to each of the four status of single parenthood, indicating no significant differences among the various status of single parenthood.

\subsection{Hypothesis 4}

Students' perception of health skills to be acquired in Environmental Sanitation is not significantly influenced by the educational qualification of parents. Data testing this hypothesis are contained in Table 5. 
Table 5: ANOVA for the Effect of Educational Background of Parents on Students' Perception of Health Skills to be acquired in Environmental Sanitation.

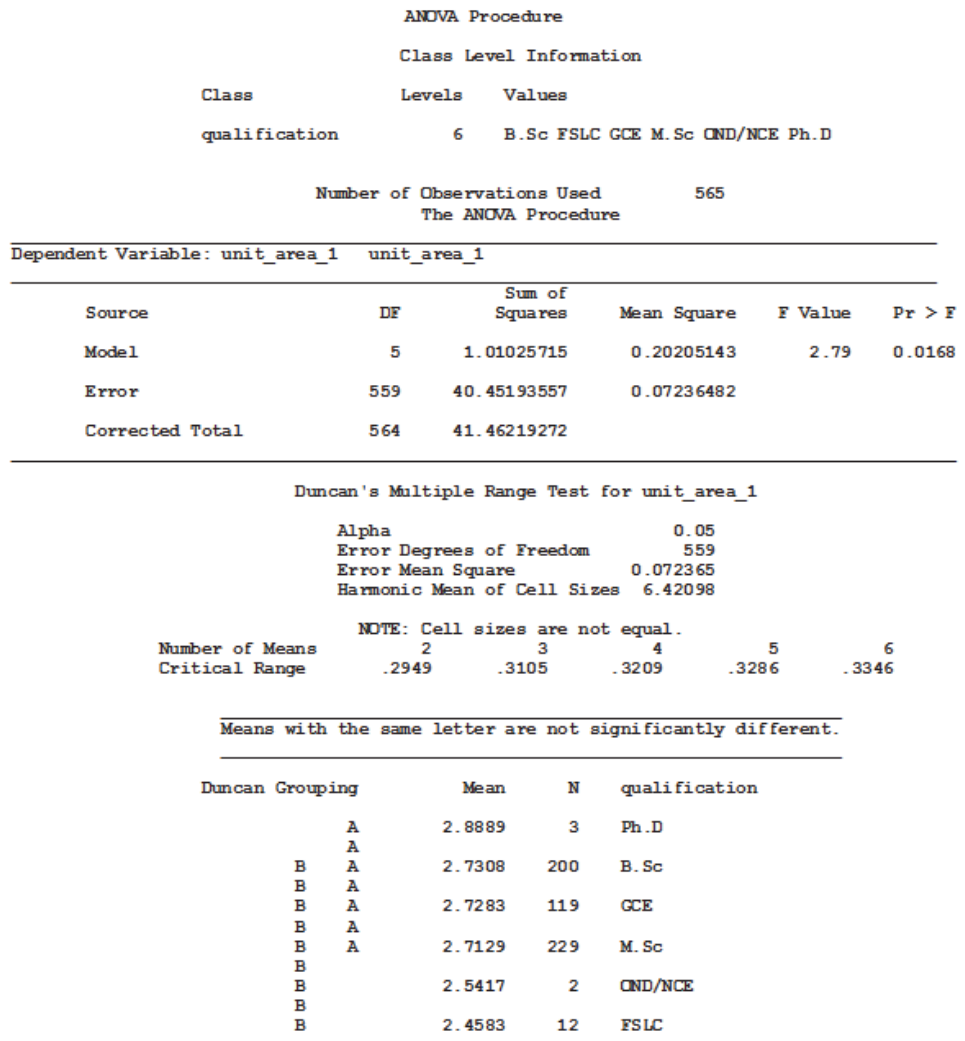

Table 5 shows that students, whose parents hold a Ph.D. degree have the highest mean score of 2.89 This is followed by students whose parents hold B.Sc degree ( $\left.x^{-}=2.731\right)$, GCE $\left(x^{-}=2.728\right)$, M.Sc degree $\left(x^{-}=2.71\right)$, and students whose parents hold OND/NCE

$\left(\bar{x}^{\bar{x}}=2.54\right)$. Students, whose parents hold FSLC $\left(\bar{x}^{-}=2.46\right)$ have the lowest mean score. These means fall between the range of 2.50-3.00 indicating that students hold parents with these educational qualifications considered the items to be very important.

Furthermore, the Table gives the F-value for the mean differences as 2.79 with a significance probability of 0.0168 , which is less than 0.05 . Thus the test is significant at $5 \%$ level of significance. We therefore conclude that students' perception of health skills to be acquired in Environmental Sanitation is significantly influenced by the educational qualification of parents. The Duncan's multiple range t-test reveals that:

(a) The perception of students whose parents hold a Ph.D. degree is significantly higher than that of those whose parents hold OND/NCE, in terms of students' perception of health skills to be acquired in Environmental Sanitation since the two groups of students have different Duncan's grouping letters, A and B, respectively.

(b) The perception of students whose parents hold a Ph.D. degree is significantly higher than that of those whose parents hold FSLC, in terms of students' perception of health skills to be acquired in Environmental Sanitation through, since the two groups of students have different Duncan's grouping letters, A and B, respectively.

(c) Similarly, significant differences in the perception of other pairs of groups of students with different parental educational qualifications exist if the students' groups have different Duncan's grouping letters. Otherwise, no significant differences exist. 


\subsection{Hypothesis 5}

The person responsible for family health care does not significantly contribute to students' perception of health skills to be acquired in Environmental Sanitation. Data testing this hypothesis are contained in Table 6

Table 6: ANOVA for the Effect of Family Health Care Provider on Students' Perception of Health Skills to be acquired in Environmental Sanitation

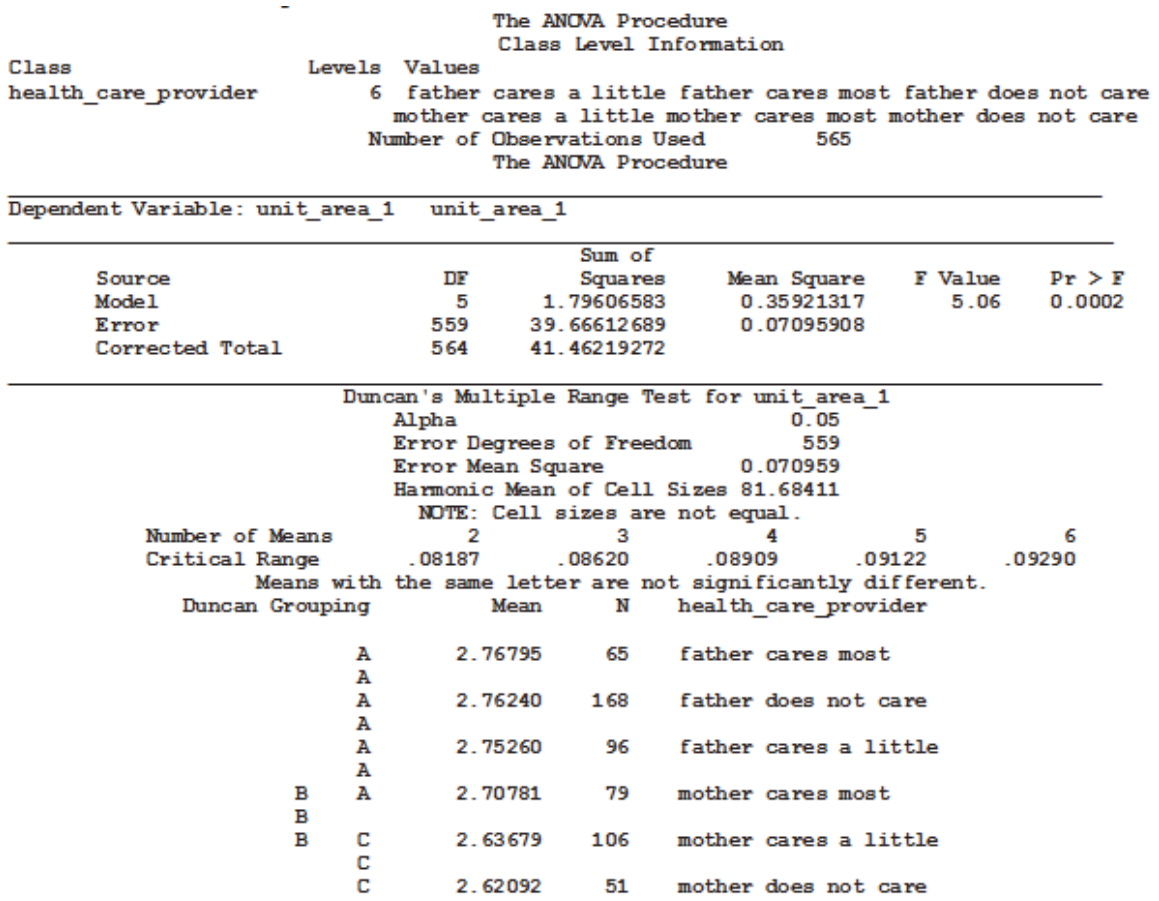

Table 6 shows that students, whose fathers care most $\left(x^{-}=2.77\right)$ have the highest mean score. This is followed by students whose fathers do not care $\left(x^{-}=2.76\right)$, whose fathers care little $\left(x^{-}=2.75\right)$, whose mothers care most $\left(x^{-}=2.71\right)$, and students whose mothers care a little $(x=2.64)$. Students, whose mothers do not care, have mean score of 2.62 . This implies that these categories of students perceived health skills to be acquired in environmental sanitation as very important.

Furthermore, the table gives the F-value for the mean differences as 5.06 with a significance probability of 0.0002 , which is less than 0.05 . Thus the test is significant at $5 \%$ level of significance. We, therefore, conclude that the persons responsible for family health care significantly contribute to students' perception of health skills to be acquired in Environmental Sanitation the Duncan's multiple range t-test reveals that:

(a) The perception of students whose fathers care most is significantly higher than that of those whose mothers do not care, in terms of students' perception of health skills to be acquired in Environmental Sanitation, since the two groups of students have different Duncan's grouping letters, $A$ and $C$, respectively.

(b) The perception of students whose fathers care most is significantly higher than that of those whose mothers care a little, in terms of students' perception of health skills to be acquired in Environmental Sanitation, since the two groups of students have different Duncan's grouping letters, $A$ and $B$, respectively.

(c) Similarly, significant differences in the perception of other pairs of groups of students with different family health care providers exist if the students' groups have different Duncan's grouping letters. Otherwise, no significant differences exist. 


\section{Discussion}

\subsection{Environmental Sanitation Skills}

Students and teachers perceived all the environmental sanitation skills as very important $\left(x^{\bar{x}}=2.72\right)$ for the acquisition of skills for health (Table 1.1). Teaching for health is one viable function of the health teacher in school. Health is considered as one of the fundamental human values. (Ziegler, 1975). Historically, emphasis on personal hygiene goes hand in hand with environmental sanitation.. Acquisition of environmental health skills among adolescents is the main thrust of this section. Just as life skills is a recent development in education literature, so also skill- based health education is a recent development in WHO's (World Health Organization) literature (Federal Ministry of Education (2006). Acquisition of skills for health is focussed on the unit areas of health education one of which is environmental sanitation.

Students perceived all the environmental health skills as very important. This result was highly exacted because of the glaring degree of environmental degradation in the Nigerian community; this cost the government exorbitant amount of money annually. Nzeagwu and Nkiochaa (2000) asserted that what constitutes environmental degradation is improper application of environmental sanitation skills. This even involves lack of skill in every level of management of waste disposal commencing from the individual. This encompassed improper disposal of refuse and sewage as well as pollution of air, water and noise.

Olusolu (1994) corroborated with the environmental sanitation skills by asserting what constitute environmental sanitation. Substantiating the above, Environmental Sanitation Policy (2010) outlined environmental sanitation to include; solid waste disposal, excreta or sewage disposal, adequate potable water supply, school sanitation, personal hygiene and pest and vector control. This requires environmental education to be accomplished and education in this area demand skill acquisition.

Stapp (1974) reported a study in environmental education in Toledo. The result of the study revealed the need for environmental education in schools. Though this was some decades ago, environmental health is passing through a transition phase of environmental education to environmental health skills. Obemcate, Akumbulu and Soclan (1990) in Ibhadodo (2010) confirmed that good sanitation improves quality of life, reduce death rate and increase life expectancy. This corroborates the findings of the parent study that acquisition of environmental skills is an essential tool for optimal health.

Okere (2011) conducted a study on health instruction in schools in Imo State. He reported that community and environmental health scored only $57.9 \%$ of the major health topics addressed in secondary schools in the state. These topics were taught for acquisition of health knowledge but bias towards acquisition to health skills was not there. This confirmed the need for environmental sanitation in schools

The study revealed that gender, educational qualification of parents and person responsible for health care in the family were significant in the acquisition of environmental health skills among students. The female gender was predominant over male in their perception of gender as a significant factor in the acquisition of environmental health skills. This may probably be that females like decent environment more than males or that it has always been their responsibility culturally to maintain the sanitation of the environment where ever they are.

Parental educational qualification has been a veritable factor in skill acquisition because of the encouragement they normally give to their offspring. Nigerian government has always encouraged social mobility of parents, not just for the demand of their carrier but also covertly for the impact they make in the lives of their offspring/wards Duncan test revealed that parent with higher qualifications attracted more attention than those with lower qualifications in acquisition of environmental sanitation skills,

The person responsible for family health is also significant in the acquisition of skill for health. The father of the household seems to win this recognition according to Duncan test. This may be attributed to the fact that men exact discipline and provide the finance during the growing years of the child in the family. Normally adolescents view them as role models.

However, family types and status of single parenthood were not significant in the acquisition of environmental sanitation skills. This may be attributed to the warped nature of family typology today whereby, female headed families are increasing gradually not as a result of death but rather as result of economic demands in sustaining family existence. Even when the couple coexists under the same roof, relationship between them negatively influence the loyalty of their wards to them. These invariably affect environmental sanitation in homes 


\section{Conclusion}

The study was on students' perception of acquisition of environmental sanitation skills among adolescents in Imo State through the school health programme. The study revealed that all the items presented in the study were perceived to be very important environmental sanitation skills by students. These covered water pollution, food handing, and environmental cleanliness. Gender, educational qualification of parents, and person responsible for family health were significant in the acquisition of environmental sanitation skills while family typology and status of single parenthood had no influence on acquisition of health skills. The perception of students whose parents hold PhD was significantly higher than those with ordinary National Diploma (OND), Nigeria Certificate in Education (NCE) and First School Leaving Certificate (FSLC). The perception of those whose father cares most was significantly higher than those whose mother does not care or cares a little. In view of the results of the study, it was recommended that the Ministry of Education should develop procedures for inculcating these skills in adolescents as a way of life and as a school requirement for graduation. Parental responsibility in health care is fundamental in acquisition of health skills. Male students should be made to realize that environmental health skill is everybody's responsibility.

\section{References}

Afoke E.N (2012).Issues in environmental sanitation: a brief review of the literature. Nigerian Journal of Health Education 16 (1), 110120.

Conjecture Corporation (2003). Environmental Sanitation Skill definition: www.wisegeck.org,what is environmental sanitation skill Retrieved 04/05/2013.

Environmental Health Practitioner Manual (2010), Methods of Sewage/Excreta Disposal,

Ibhadode,C.A.E. (2010).Human waste disposal in market place environment in Edo State. Nigerian Journal of Health education 14 (1),171-184.

Ilo, C.I \& Mbama, 1(2012) Environmental Education as a strategy for sustainable development and promotion in Nigeria, Nigerian Journal of Health education 16 (1), 49-60

Kwasan, I.J. (2012). The role of schools in promoting environmental health in southern senatorial zone of Kaduna State. Nigeria Journal of Health Education 16 (1), 321-332.

Last, J.M. (1995). A dictionary of Epidemiology (3rd ed). New York. Oxford University Press.

Nzeagwu, R \& Nkwocha, F.(2000).School health provision in primary schools in Obudu Obudu urban. Nigerian School Health Journal (11), 49-57.

Trevithick P. (2011). Social work skills: a practice handbook New York mixed sources

O' Hagan, K. (2000). Crises interaction, in M. David (ed). Encyclopaedia of social work Oxford. Oxford University Press

Offing, J.O. 2011. The dilemma of implementing effective environmental policies in Nigeria, JORIND 9 (1), 420-431

Ogueri E.O \& Oparah J.S. (2007). Solid waste generation and management practices as correlates of health status of people in Owerri Municipal, Imo State. Nigerian School Health Journal 19(2),48-59.

Okere G.N. (2011). Level of health education instruction among senior secondary school in Imo State, Nigeria.. Nigerian Journal of Health Education, 14(1): 192-202.

Omorogiwa, T.B.E \& Omorogiwa, K.O. (2009). Impact of single parenthood on the academic performance of children. Journal of Gender Studies 1(2) 169-174.

Popoola A. (2009). Influence of Gender and classroom climate on secondary school students achievement in mathematics and mathematics related subjects in Ekiti State, Nigeria Journal of Gender Studies 1(2), 129 -137.

UNICEF (1999). Towards a better programme; a manual on hygiene promotion, -water and environmental sanitation. New York, Technical guideline series, 6, 1-82

World Bank Group (2012). Definition of Environment: http://go.worldbank.org/xonhvfztio Retrieved 13/12/2012

World Health Organization \& United Nations International Children Emergency Fund (UNICEF), (2000). Improved Water Source: en.wikipedia.org/wiki./improvedwater... Retrieved 07/02/2013.

Ziegler, E.F. (1975). The health teacher needs a philosophy. In D.A. Read (ed). New direction in health education: some emergency contemporary issues for the emerging age. New York: Macmillan. 